Francisco José López Alfonso:

Profesor titular de la Universitat de València, es autor de los libros: César Vallejo, las trazas del narrador (Valencia, 1995), Hablo, señores, de libertad para todos. López Albújar y el indigenismo en el Perú (Alicante, 2006) y Sombras de la libertad. Una aproximación a la literatura brasileña (Alicante, 2008). Es igualmente editor y prologuista del volumen Indigenismo y propuestas culturales en el Perú: Belaúnde, Mariátegui y Basadre (Alicante, 1995)
1

Citado por Julio Ortega, «Tránsito de Ventura García Calderón», en Julio Ortega, Crítica de la identidad, México, D. F. FCE, 1988 (pp. 69-92), p. 73.

2

Luis Loayza, "Colónida en el pleito generacional», Sobre el 900, Lima, Hueso húmero ediciones, 1990 (pp.135-145), p. 136.

Citado por Loayza, op. cit., p. 137

Mirko Laver, El sitio de la literatura. Escritores y política en el Perú del siglo XX, Lima, Mosca Azul editores, p. 23
Narrativa indigenista y racismo: Ventura García Calderón, Enrique López Albújar y Luis E. Valcárcel FRANCISCO JOSÉ LÓPEZ ALFONSO

\title{
NARRATIVA INDIGENISTA Y RACISMO: VENTURA GARCÍA CALDERÓN, ENRIQUE LÓPEZ ALBÚJAR Y LUIS E. VALCÁRCEL
} FRANCISCO JOSÉ LÓPEZ ALFONSO

Universitat de València

\author{
Con la raza no me aclaro \\ Karl Kraus, «Aún así es judío», Escritos.
}

En 1932, escritores franceses, belgas y españoles de primer nivel propusieron el nombre de Ventura García Calderón para el premio Nobel ${ }^{1}$. Sin embargo, hoy sus libros son difíciles de encontrar. Podría pensarse que se trata de un caso más de esos escritores celebérrimos en su momento a los que el tiempo, por la razón que sea, ha relegado al olvido. ¿Quién recuerda hoy al novelista y dramaturgo británico John Galsworthy, premio nobel justamente en 1932?

El caso de Ventura García Calderón, sin duda, el mejor escritor vinculado al grupo del 900 , parece distinto, porque el lugar que debería ocupar en la literatura peruana, entendida como institución, allá entre 1920 y 1930 ya era un lugar vacío. Intelectuales coetáneos y también ligeramente más jóvenes, los miembros de la generación de la Reforma Universitaria, integrada en buena medida por los nuevos sectores medios procedentes de la provincia, pero igualmente de Lima, combatieron por afirmarse en una actividad -la literatura-, que había sido parte importante de la legitimación ideológica de los grupos dominantes, desplazando a los novecentistas. La agresividad con la que se emplearon fue notable. Bastaría recordar el artículo de Federico More, «La hora undécima del señor Ventura García Calderón», publicado en los números 2 y 3 de la revista Colónida, que, como ha señalado Luis Loayza, no es una crítica literaria sino un ajuste de cuentas ${ }^{2}$, «porque -el mismo More lo advertía- el sr. Ventura García Calderón representa en París los intereses de determinado grupo literario que hay en Lima» ${ }^{3}$.

En cierto sentido, esta belicosidad fue innecesaria, pues si bien la idea de cultura nacional y su manejo había sido obra de los novecentistas en la primera década del siglo $\mathrm{XX}$, en algún momento entre el primer y el segundo decenio lo oficial opera "como un espacio vacio, es decir: sin obras de impacto, sin activismo influyente, sin propuestas capaces de generar seguidores y de desarrollarse, sin público y sin instituciones» ${ }^{4}$. Los novecentistas carecieron de esa intuición práctica que permite influir sobre la realidad y modificarla. En cualquier caso, su conversión en enemigos, en hispanistas, les permitió especialmente a los jóvenes de la Reforma Universitaria, presentarse como lo nuevo frente a lo viejo, dando a las ideas de nación, indio y modernidad un contenido completamente distinto. El frente común, sin embargo, no tardaría en evidenciar lo coyuntural de su alianza, revelando la diversidad de proyectos que incluía.

Pero, ahora, lo que quisiera destacar es la contundencia de esa derrota. Situados bajo el rubro de lo viejo, los novecentistas no sólo quedaron deslegitimados ideológicamente, sino que fueron todos convertidos en la misma cosa, borrando diferencias y hasta discre- 
pancias entre ellos. La demoledora crítica de Mariátegui en «El proceso de la literatura» a Riva Agüero y su Carácter de la literatura del Perú independiente podría ilustrar esta expulsión de los novecentistas de la historia de la literatura peruana, su reducción a la versión más conservadora representada por Riva. Víctor Andrés Belaúnde, el único del grupo que tuvo capacidad de respuesta, se quejó de ello en $L a$ realidad nacional. También denunció el ardid que significó referirse a la generación como «futurista, tratando, intencionadamente, de confundirla con el partido que llevó ese nombre» y su deliberada omisión de un autor como Ventura García Calderón para «presentar como infecunda y mediocre» a esta generación ${ }^{5}$.

El destierro de los novecentistas -incluido Ventura García Calderón- de las letras nacionales fue completado por La literatura peruana, de Luis Alberto Sánchez, aparecida en 1928-1929 y reelaborada en varias ocasiones. Escrita con idéntico sentimiento antioligárquico, el ensayo de Sánchez ha fijado el corpus de la literatura en el Perú; pues, si los sucesivos programas oficiales de enseñanza nunca han seguido al pie de la letra su índice, la influencia es obvia ${ }^{6}$. Hasta hoy, la mayor parte de las ideas vigentes sobre literatura nacional provienen de esta obra ${ }^{7}$.

Pero conviene recordar que esas ideas, en buena medida fueron elaboradas para derrocar a los novecentistas. Continuar repitiéndolas sin someterlas a crítica, cuando el adversario ya no existe, es reescribir un flaubertiano diccionario de las ideas recibidas.

Y así, por ejemplo, un estudioso tan reputado como Antonio Cornejo Polar, remitiendo a La venganza del cóndor, insiste en que en este texto queda marcada la «adhesión [de Ventura García Calderón] a un estado social y la defensa de los intereses de los grandes señores andinos» ${ }^{8}$. Si lo relativo a esa adhesión debería, cuando menos, explicarse con más detalle, lo que dice sobre la defensa de los intereses de los grandes señores andinos es palmariamente un error.

A diferencia de lo que suele ocurrir con la narrativa indigenista de las décadas del veinte y del treinta, cuya simplicidad promueve una fuerte ideologización de sus mensajes, convirtiéndola en lo que Marx llamó arte de tendencia, los relatos de García Calderón son menos evidentes en su función social. Pero si algo queda claro en ellos es su condena inapelable de estos terratenientes andinos que hacen del látigo la expresión de su poder: «Por toda respuesta el amo aludió al excelente chicotillo con que castigaba a los atrevidos», leemos en «La momia»?.

La causa de esta condena no se oculta. Estos gamonales tienen su propia ley y amenazan la unidad del estado, transformando el Perú en una suma de pequeñas republiquitas, en una suerte de país semifeudal.

...la raza de los Montalván, raza hermosa y bravía de jinetes rencorosos, que se exterminaban impune y recíprocamente por querellas de agua de riego o de política, en la soledad de un cañaveral. ¡Quién iba a condenarlos, si eran ellos los caciques del departamento, diputados o senadores que con la amenaza de revolución hacían temblar en Lima a los presidentes!10.

Se equivoca Cornejo cuando afirma: «En términos ideológicos -no literarios- la obra de García Calderón parecería anterior a Aves sin nido» ${ }^{11}$. Al contrario, La venganza del cóndor es un testimonio más de esa vieja lucha entre Lima, como foco irradiador de civilización, y las bárbaras provincias, de la que Aves sin nido fue quizá su primer fruto novelesco. Ya en la primera página del relato que da título al volumen nos encontramos con un personaje-narrador limeño que se identifica con el sufrimiento indígena, como lo hacía la familia Marín, para que la condena del poder andino resulte inapelable: «El militar le rasgó la frente de un latigazo. El indio y yo nos estremecimos» ${ }^{12}$.

Al margen de la instrumentalización que García Calderón haga del problema indígena, sorprende la lectura tan estrecha que Cornejo hace de un cuento como "Amor indígena» para caracterizar ideológicamente al novecentista.

«El cuento de García Calderón -para Cornejo- no tiene desperdicio» ${ }^{13}$. En él se narra cómo tres blancos llegan a una aldea serrana que celebra la fiesta del santo patrón. Uno de ellos, un hacendado, dispara sobre un Buda en un tambo, tirotea a un carnero porque le da la gana y luego dispersa a latigazos a los indios para que, finalmente, el narrador pueda violar a una muchacha india de la que se ha encaprichado:

Aquello fue salvaje, como en las historias de la Conquista. Me encerré, despedí al chino aterrado,

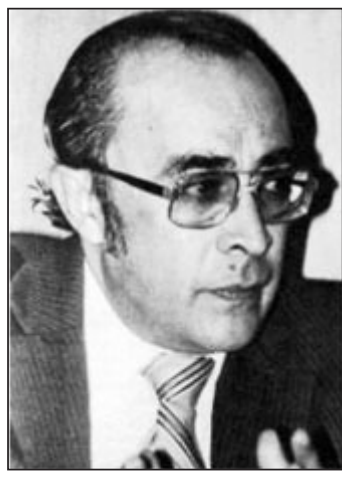

Antonio Cornejo Polar.

5

Víctor Andrés Belaúnde, La realidad nacional, vol. III de las Obras Completas, Lima, Edición de la Comisión Nacional del Centenario de Víctor Andrés Belaúnde, 1987, pp. 134 y 137

6

Laver, op. cit., p. 57

7 Ibid., p. 10.

8

Antonio Cornejo Polar, Literatura y sociedad en el Perú: la novela indigenista, Lima, Lasontay, 1980, p. 48.

9

Ventura García Calderón, «La momia», en La venganza del cóndor (1919), Madrid, Sucs. de J. Sánchez Ocaña y Cía., 1948 (pp. 15-22), p. 19.

10

García Calderón, «Murió en su ley», en op. cit. (pp. 23-30), p. 26.

11

Cornejo Polar, op. cit., p. 47.

12

García Calderón, «La venganza del cóndor», en op. cit. (pp. 7-12), p. 7.

13

Antonio Cornejo Polar, La formación de la tradición literaria en el Perú, Lima, CEP, 1989 p. 82.

Narrativa indigenista y racismo: Ventura García Calderón, Enrique López Albújar y Luis E. Valcárcel FRANCISCO JOSÉ LÓPEZ ALFONSO 
14

García Calderón, «Amor indígena» en op. cit. (pp. 49-54), pp. 53-54.

\section{5}

Cornejo Polar, La formación .... op.cit., p. 82.

16

García Calderón, «Amor indígena» en op. cit., p. 52.

\section{7}

Luis Valcárcel, «El amor de don Rodrigo», en Tempestad en los Andes (1927), Lima, Editoria Universo, 1972 (pp. 75-77), p. 77.

18

García Calderón, «A la criollita» en op. cit. (pp. 133-137), p. 134.

19

Manuel González Prada, «Discurso en el Politeama», Pájinas Libres. Horas de Lucha, Barcelona, Editorial Ayacucho, 1985 (pp. 43-48), pp. 45-46.

20

García Calderón, «La venganza del cóndor» en op. cit. (pp. 7-12), p. 12.

21

García Calderón, «La momia» en op. cit. (pp. 15-22), p. 16.

\section{2}

García Calderón, «Fue en el Perú» en op. cit. (pp. 99-103), pp. 99-100.

23

Citado por Ortega, op. cit., p. 83.

24

José de la Riva Agüero, Carácter de la literatura del Perú independiente, Lima, E. Rosay Editor, p. 143.

25

ld.

26

Id.

Narrativa indigenista y racismo: Ventura García Calderón, Enrique López Albújar y Luis E. Valcárcel FRANCISCO JOSÉ LÓPEZ ALFONSO y la indiecita fue mía sollozando palabras que yo no acertaba a comprender. Estaba primorosa con su alucinado temor y su respeto servil al hombre blanco. Me alentaba por primera vez esa alegría de los abuelos españoles que derribaban a las mujeres en los caminos para solaz de una hora y se alejaban ufanos a caballo, sin remordimiento y sin amor. La linda niña me miraba sumisa como a su dueño $0^{14}$.

Para Cornejo, en este cuento cristaliza «el hispanismo duro y beligerante» y, aún más, en él se «traza un paradigma intemporal en el que la conquista se repite una y otra vez» ${ }^{15}$.

En mi opinión, lo que escandaliza a Cornejo es precisamente lo que García Calderón quería denunciar. De ahí la mención del salvajismo de la violación, de la ausencia del remordimiento, de la desolación indígena: «El mundo entero pertenece a los que tienen tan buen revólver. ¿Por qué nos iba a inquietar la desolación indígena?» ${ }^{16}$.

García Calderón cede la voz a un gamonal de espíritu para que sea él solo quien se deslegitime moralmente, sin necesidad de denunciarlo. La imagen que se ofrece de los hacendados serranos en otros cuentos del libro, me parece, confirma esta lectura.

Me pregunto si la interpretación de Cornejo hubiese sido la misma si el cuento, si el libro no hubiese estado firmado por Ventura García Calderón. Por lo que sé, nada extraño halló Cornejo en «El amor de don Rodrigo», un relato incluido en Tempestad en los Andes, del indigenista Luis E. Valcárcel, en el que un gran señor terrateniente se enamora de una campesina indígena y se casa con ella; un relato que concluye con estas humillantes palabras: «Cuando el caballero llegó a la estancia nupcial, La Raza dignificada lloró con lágrimas de gozo el avatar» ${ }^{17}$.

$Y$ es que García Calderón no es tan conservador como Riva Agüero, con cuyo pensamiento se le quiere identificar forzadamente. Lejos de las reservas que Riva tiene hacia González Prada, en García Calderón se percibe su influencia en la presencia de esa «trinidad embrutecedora del indio» en algunos cuentos. Incluso hay uno, «A la criollita», en el que se denuncia la brutalidad de los conservadores en las ciudades serranas, que terminan asesinando al periodista liberal, «un hereje de Lima que leía los libros de González Prada» ${ }^{18}$.

Desde luego, esto no significa que la cuestión social del indígena, tal como la planteaba
González Prada, haya calado profundamente en Ventura; pero no deja de percibirse su influjo. El relato «La venganza del cóndor» se hacía eco de la provocadora afirmación que se lee en el «Discurso en el Politeama»: «(...) la nación está formada por las muchedumbres de indios diseminados en la banda oriental de la cordillera» ${ }^{19}$. Con culpable conciencia, el narrador se refiere a los hombres blancos como «los intrusos que somos nosotros» 20 . La misma culpabilidad ante la historia se expresa en otros cuentos. En «La momia», leemos: «Cuatro siglos de espanto les han hecho aceptar la peor tragedia, suspirando» ${ }^{21}$. O de manera aún más explícita en «Fue en el Perú»:

Los blancos somos en el Perú, para la gente de color, responsables de tres siglos injustos. Vinimos de la tierra española hace mucho tiempo y el indio cayó aterrado bajo el relámpago de nuestras espingardas. Después trajimos en naos de tres puentes, del Senegal o de allende, con cadena a los pies y mordaza en la boca, las «piezas de ébano», como se dijo entonces, que bajo el látigo del mayoral gimieron y murieron por los caminos ${ }^{22}$.

Al margen de esta mala conciencia-quizá no muy angustiada- y de su uso para discriminar a los bárbaros terratenientes provinciales de la civilizada burguesía limeña, la imagen que se ofrece del indio es muy superficial. Ventura se acerca a él como escritor modernista, esto es, con una mirada estética - «nuestro aporte de fantasía a la imaginación del Universo", diráa ${ }^{3}$ - y no como un escritor regionalista, es decir, como un escritor que se plantea el problema de la modernidad en el ámbito rural.

Aunque su visión del indio repita prejuicios del ambiente y de la época, García Calderón está lejos del racismo de Riva Agüero. Sabe del conflicto entre blancos e indios, pero no cree, como Riva, que en la sierra palpite «secreta y pérfidamente una hostilidad recelosa y siniestra» ${ }^{24}$. No cree, como Riva, «que en él, como en todos los esclavos, fermenten odios mortales e inextinguibles» ${ }^{25}$. Pero sí comparte con el líder del partido futurista un imaginario exótico sobre el universo indígena. «Las leyendas -escribía Riva- hablan de envenenamientos misteriosos, de encantamientos, sortilegios y maleficios» ${ }^{26}$. Y en La venganza del cóndor encontramos esto mismo en cuentos como «La llama blanca», en el que un 
hacendado, que mata a una hermosa llama -la Killa- para dar una lección a los indios que mantienen relaciones sexuales con el ganado, se enamora de este animal que parece haber resucitado y contrae una terrible enfermedad en su rostro a causa de un escupitajo de la llama; o en "La momia», en el que otro hacendado, empeñado en añadir la momia de una princesa incaica a su colección prehispánica, se encuentra a su propia hija momificada.

Pero aquí, no hay nada de «diabólico», como decía Riva ${ }^{27}$. Este indigenismo exotista -como el orientalismo, una clara invención occidental- es sólo una manifestación más del cosmopolitismo modernista, aunque en este caso se trate de un exotismo interior ${ }^{28}$.

Ello se advierte más claramente cuando se recuerda que La venganza del cóndor se publicó en Madrid en 1924 y que apenas un año después se tradujo al francés y, sobre todo, que fue escrita para un público europeo. Marcas del tipo "de mi tierra», repetidas en muchos relatos, así lo confirman; pero ninguna más clara que este ejemplo de «Historia de caníbales»: «Ésta es la parte de mi relato más difícil de explicar en Europa ${ }^{29}$.

Creo que es este factor-escribir para Europa- el que condiciona su imagen del mundo indígena, y todo lo que se diga de ésta tendrá que considerarlo inevitablemente. $Y$ es lo que explica en buena medida su reconocimiento y éxito entre europeos. «¿Qué conocíamos del Perú antes de que lo hubiésemos explorado en los libros escritos por usted?», le preguntaba el Conde de Carton de Wiart en su discurso de recepción en la Real Academia de Bélgica ${ }^{30}$. Ventura acomodó su perspectiva a los deseos de sus lectores que con el exotismo, como antítesis de la artificialidad de la vida europea, se apropiaban «inocentemente» de otras culturas. Incluso llegó a reproducir ese estrabismo característico de la metrópolis en su mirada a otros pueblos: atracción/repulsión. Para Ventura, los aborígenes de la selva representan, por contraste con el mundo civilizado, la armoniosa sociedad natural. Son esos buenos salvajes, que tienen su precedente más ilustre quizá en Montaigne, a cuyo ensayo parece remitir tanto el título como el contenido del citado «Historias de caníbales»:

Muy deprisa aprendió [la indiecita] algunas palabras en español, tres sobre todo que pronunciaba bien: sucios, embusteros y ladrones, las cuales resumían para ella la civilización. En realidad había pasado su juventud bañándose desnuda durante el santo día en las riberas; decía siempre la verdad, y el robo no existe en las costumbres de los salvajes de mi tierra ${ }^{31}$.

Sin embargo, la imagen que ofrece del indio de la sierra, descendiente del inacario, no es tan amable. Si el indio del Amazonas es el hombre natural, el indio de la sierra representa al hombre civilizado que ha experimentado una regresión cultural; algo muy similar a la distinción que Chateaubriand establecía entre el salvaje americano y el árabe ${ }^{32}$.

Pero conviene recordar que ese estado es, para Ventura, la «injusta ruina de la raza» ${ }^{33}$. Y que esa «resignación de los vencidos» ${ }^{34}$, esos «siervos de una raza inerme» ${ }^{35}$, esa «raza que nunca supo sublevarse» ${ }^{36}$ son, en buena medida, expresiones negadas por el comportamiento de sus personajes indígenas que, desde su opresión, intentan vengar las humillaciones de que son víctimas. «La venganza del cóndor» o "Coca» serían ejemplos de ello e insinuarían una realidad social en la que el estado es impotente para cumplir con sus obligaciones.

Quizá Mariátegui pensara en García Calderón cuando escribió: «Los indigenistas auténticos -que no deben ser confundidos con los que explotan temas indígenas por mero 'exotismo'- colaboran, conscientemente o no, con esta obra política y económica de reivindicación -no de restauración ni de resurrección» ${ }^{37}$.

En mi opinión, el indigenismo de Ventura es exótico, pero aún así contribuyó, aunque fuese modestamente, a la reivindicación de la causa indígena. Pero éste fue un mérito que los intelectuales provincianos coetáneos $\mathrm{y}$, sobre todo, la generación posterior quisieron reservarse de manera exclusiva para sí, haciendo de los novecentistas, sin excepción, un grupo de encomenderos.

Prejuiciosa, pero fundamentalmente exótica, la mirada de Ventura más que racista es aristocrática. De hecho, apostó de manera contundente por «el cholo, es decir, el mestizo cuando no se avergüence de serlo ni crea íntimamente que el blanco es de raza superior ${ }^{38}$, cuya concreción vio en Rubén Darío. No creyó, sin embargo, que el mestizaje fuese una identidad «desproblematizada», como creía Cornejo $^{39}$. En el cuento «Fue en el Perú», la negra Simona le cuenta al narrador blanco que el niño Jesús nació en el Perú y que era un mestizo de piel oscura, que la virgen era
27 lbid., p. 144.

28

Conviene advertir que este imaginario, procedente del folklore según Riva, lo encuentra García Calderón, al menos parcialmente, en las tradiciones indígenas de Ricardo Palma.

29

García Calderón, «Historia de caníbales», en op. cit. (pp. 73$80)$, p. 76.

30

Citado por Ortega, op. cit., p. 73.

31

García Calderón, op. cit., p. 77.

32

Véase F-R de Chateaubriand, De París a Jerusalén, Barcelona, Laertes, 1982, p. 202.

33

García Calderón, «La llama blanca», en op. cit., p. 93

34

García Calderón, «La venganza del cóndor», en op. cit., p. 12.

35

García Calderón, «Amor indígena», en op. cit., p. 49

36

García Calderón, «Los cerdos flacos», en op. cit., p. 69.

37

José Carlos Mariátegui, «El proceso de la literatura», en Siete ensayos de interpretación de la realidad peruana (1928) vol. 2 de las Obras Completas, Lima, Editorial Amauta, 1986 (pp. 229-350), p. 332

38

García Calderón, en «Materiales para un discurso a la nación pervana», citado por Ortega op. cit., p. 86

39

Véase Antonio Cornejo Polar, Escribir en el aire, Lima, Editorial Horizonte, 1994, p. 20.

Narrativa indigenista y racismo: Ventura García Calderón, Enrique López Albújar y Luis E. Valcárcel FRANCISCO JOSÉ LÓPEZ ALFONSO 


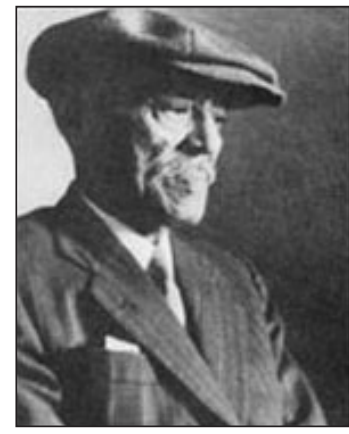

Enrique López Albújar.

40

García Calderón, «Fue en el Perú», en op. cit., p. 103.

41

García Calderón, «Viernes Santo criollo», en op. cit. (pp. 167 . 171), p. 171.

42

Citado por Julio Ortega, op. cit., p. 92.

43

$Y$ respondió con un contundente y extenso artículo, «Tres epítetos gruesos y una exageración verdadera». Véase Raúl-Estuardo Cornejo, López Albújar, narrador de América, Madrid, Anaya, 1961, principalmente pp. 97 y 98.

44

Luis Alberto Sánchez, «Batiburrillo indigenista», en Manuel Aquezolo (comp.), La polémica del indigenismo, Lima, Mosca azul Editores, 1976 (pp. 6973), p. 71.

45

Sánchez, «Respuesta a José Carlos Mariátegui», en Aquezolo, op. cit. (pp. 77-81), p. 80 .

Narrativa indigenista y racismo: Ventura García Calderón, Enrique López Albújar y Luis E. Valcárcel FRANCISCO JOSÉ LÓPEZ ALFONSO una indiecita y san José, mulato, y que los tres reyes que vinieron a adorarlo eran un prefecto blanco, un indio cacique y un esclavo negro, rey de los mandingas. Pero que los blancos lo mataron:

Pero todos sabemos que Su Majestad murió y resucitó después y se vendrá un día por acá para que la mala gente vean que es de color capulí como los hijos del país. Y entonces mandará afusilar a los blancos y los negros serán los amos, y no habrá ni tuyo ni mío, ni levas, ni prefetos, ni tendrá que trabajar el pobre para que engorde el rico... ${ }^{40}$.

Parece inevitable pensar en la raza cósmica de Vasconcelos; pero, desde luego, Ventura es consciente de que el mestizaje, aun siendo la única vía razonable, no es una «solución» exenta de problemas.

En suma, si Ventura es racista, el suyo es un racismo superficial, bien distante del pensamiento racial y de su prolongación activa que culmina con el chivo expiatorio y la aniquilación del Otro. La suya es una posición aristocrática que mira con actitud paternalista a «toda aquella plebe simple y generosa de mi crédula tierra [que el viernes santo] se inclina al pasar y dice en voz baja al santo vestido de levita [san José]:

- ¡Sintiendo mucho la muerte de Don Jesús!...» ${ }^{41}$.

Ello concuerda con su concepción del escritor como miembro de una élite que debe ejercer la máxima representación del espíritu de un pueblo. "Comprender la patria -dirá en Nosotros- como sostén y garantía de la eternidad aquí abajo» ${ }^{42}$. La patria, esto es, el orden jerárquico del país como expresión del inalterable orden celeste, una concepción cuasiestamental de la sociedad, algo que se aproxima mucho a ese proyecto político que Belaúnde definió como tradicionalismo dinámico o evolutivo en su ensayo "La Historia» (1908) y que aseguraría el control del país a la oligarquía.

Una suerte similar ha corrido Enrique López Albújar, autor de Cuentos andinos (1920), marcado como infame escritor racista y encerrado en el mismo cajón de la historia. También él sintió el ataque de Colónida, aunque no perteneciese como los novecentistas a un grupo limeño coetáneo, sino a una generación ligeramente mayor y fuese un escritor de provincias. Abraham Valdelomar publicó un artículo en La Prensa, titulado «Los obreros del pensamiento» (23 de septiembre de 1916) en el que para elogiar a su generación, «fuerte, fecunda y valiosa», disminuía y hasta despreciaba los méritos de las generaciones anteriores y en especial de la inmediata. Aunque el ataque no fuese personal, López Albújar se sintió agredido ${ }^{43}$.

Algunos años más tarde recibiría otra embestida más concreta en esa batalla emprendida por los jóvenes provincianos y limeños de clase media por hacerse con el control de la institución literaria como trampolín político. La historia es conocida: en febrero de 1927, José Ángel Escalante denunciaba el carácter pintoresco y oportunista del indigenismo cultivado por los escritores costeños: «literatura de frases hechas y lugares comunes». La denuncia de Escalante apuntaba principalmente a Mariátegui. El ataque se preparaba con la crítica a ciertas afirmaciones, cuando menos discutibles «Sobre la psicología del indio» -así se titulaba el breve ensayo- expuestas por López Albújar en Amauta, la revista dirigida por Mariátegui.

$\mathrm{Al}$ intervenir en la polémica, Luis Alberto Sánchez dio la razón a Escalante en la incoherencia que significaba el amparo que los indigenistas daban a las afirmaciones de López Albújar, «destinadas a probar, según me parece, que el indio es el más despreciable ser que habita sobre la tierra» ${ }^{44}$.

Mariátegui no pudo menos que defenderse y defender el estudio de López Albújar. Sánchez volvió a la carga, recordando a su oponente que las observaciones de López Albújar se realizaron desde su perspectiva de juez de primera instancia: «¿Cómo, pues, me dice usted que esas observaciones se refieren al indio en sus relaciones con el blanco? Diga usted que se refieren al indio criminal en sus relaciones con el juez, y estamos de acuerdo» ${ }^{45}$.

Surgía así, secundariamente, un lugar común de la crítica e historiografía literarias. El del indio criminal de López Albújar. Y aunque la tesis de Sánchez se restringía al trabajo publicado en Amauta, el desplazamiento hasta Cuentos andinos resultaba fácil, pues el lector de ambos puede interpretar aquél, dadas las semejanzas semánticas y formales, como las conclusiones del volumen de cuentos. El propio Sánchez dio el paso y otros no han dudado en seguirlo hasta nuestros días. Por ejemplo, Antonio Cornejo afirmaba: 
En este ensayo interpretativo [ «Sobre la psicología del indio»], como también en sus cuentos [Cuentos andinos], López Albújar toma en consideración primeramente [...] su experiencia como juez. Experiencia que, como es obvio, no sólo recorta los límites de su conocimiento sino que fuerza una perspectiva general sobre el asunto ${ }^{46}$.

Es la lectura tantas veces repetida del indio sentado en el banquillo de los acusados; una imagen, insistía Mario Vargas Llosa, «tan negativa y deshumanizada que merece llamarse racista» ${ }^{47}$. Esta generalizada opinión explica el olvido de que ha sido objeto la obra de López Albújar, a pesar de aceptarse su carácter precursor como narrador indigenista y el vigor de su prosa.

La condena, quizá justificada en el ensayo de Amauta, carece de sentido en el caso de Cuentos andinos, pues los juicios sobre el indio no difieren esencialmente de los vertidos sobre el mestizo o el blanco. Asunto distinto es que se esté de acuerdo o no con su nada halagüeña concepción de la naturaleza humana. Pero para percibir esto es necesario no sólo liberarse de la negativa valoración que pesa sobre la obra, sino captar su carácter de conjunto. Y ello, naturalmente, resulta imposible si la lectura se realiza además desde un restrictivo y militante indigenismo, entendido como la literatura o ideología que trata exclusivamente de los indios y, como mucho, de los agravios de que son objeto por parte de los otros.

No hay otro argumento para explicar la condena que, según Tomás G. Escajadillo, merecen tres cuentos del volumen: "'La soberbia del piojo', 'El caso Julio Zimens' y 'Cómo habla la coca', relatos olvidables o disquisiciones filosófico-sociológicas sin validez narrativa» ${ }^{48}$; precisamente los tres cuentos de mistis, en los que el mundo indio sólo aparece como en eco.

Mutilaciones de este tipo hacen de Cuentos andinos apenas un revoltillo, negando el vínculo entre los diferentes relatos que perfilan su sentido en el cotejo. López Albújar insiste con meticulosidad en relacionar textos mediante la presencia o mención de personajes que han aparecido en relatos anteriores o que lo harán en los que siguen. Posiblemente, un procedimiento más sugerente sean los diversos paralelismos entre relatos. En definitiva, no es posible la adecuada interpretación de los relatos en forma aislada, extraídos del conjunto. El sentido de cada uno, los mismos juicios escandalizantes que a veces se vierten en alguno de ellos, sólo pueden ser comprendidos desde la red que todos elaboran.

Por lo demás, la clave ideológica del libro está explicitada en uno de esos supuestos «relatos olvidables»: "Todas las historias se parecen. En todas verá usted las mismas ridiculeces, las mismas vanidades, las mismas miserias, las mismas pasiones. No hay más que variantes» ${ }^{49}$. Esta universalidad del sentimiento delata la «presencia del juez López Albújar», pero en un sentido diferente al apuntado por la crítica. La afirmación iusnaturalista revela al hombre de derecho convencido de la igualdad natural entre los hombres.

¿Pero cuál es la imagen que López Albújar ofrece del indígena? El indio de Cuentos andinos se muestra como un rebelde. «Para qué es uno hombre sino para rebelarse?», se pregunta el narrador de «Cómo habla la coca»50. Mariátegui no llegó a precisarlo, pero posiblemente fuese esta rebeldía de los personajes lo que admirase en la obra de López Albújar. Esta violenta libertad era la promesa de un futuro mejor, la condena absoluta del determinismo reaccionario y de su pareja ética, el paternalismo. De ahí las esperanzadas y fustigantes palabras de don Melchor, el narrador secundario de «La soberbia del piojo»:

¡Bah! ¡Para qué son tan bestias los indios! Si los indios se organizaran y fueran más a la escuela y bebieran menos, cuántas cosas no harían! Porque el indio no es idiota; es imbécil. Pero de la imbecilidad se puede salir; de la idiotez no. La imbecilidad como usted sabe, se cura tonificando el alma, sembrando ideales en ella, despertándole ambiciones, haciéndole sentir la conciencia de la propia personalidad ${ }^{51}$.

En sus cuentos no todos los indios son iguales. La rebeldía individual de Conce Maille, que dice no necesitar que nadie le haga justicia, pues él sabe hacérsela, contrasta con el control que los yayas, amparándose en la tradición y en el supuesto carácter divino de la ley, ejercen sobre la colectividad. Hay indios ricos y otros que no lo son; indios honrados e indios mostrencos, borrachos y vagos, como Hilario Crispín, raptor y asesino.

Esta percepción plural impide que su obra incurra en el populismo frecuente en los escritores indigenistas que hacen del indio el portador de valores auténticos y de las mejores virtudes frente a la corruptora civilización

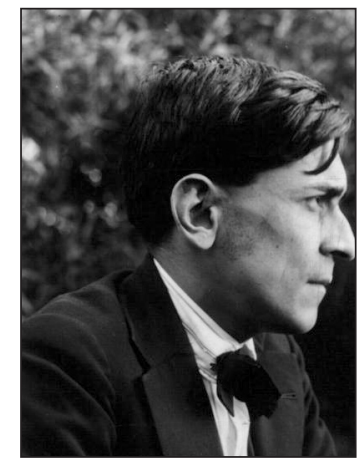

José Carlos Maiátegui.

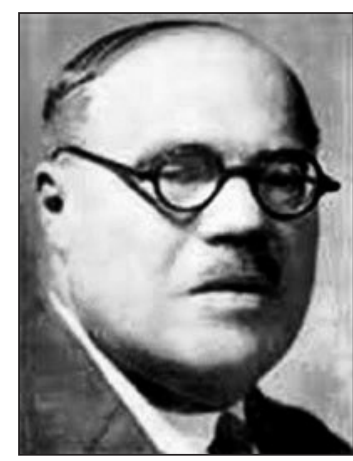

Ventura García Calderón.

46

Cornejo Polar, Literatura y sociedad..., op.cit., p. 49.

47

Mario Vargas Llosa, Discurso de investidura de doctor Honoris Causa, Universidad de Murcia, 1998, sin paginar.

48

Tomás G. Escajadillo, La narrativa de López Albújar, Lima, Conup, 1972, p. 84

49

Enrique López Albújar, «La soberbia del piojo», Cuentos andinos, Lima, Imprenta Lux, 1924 (pp. 47-61), p. 52.

50

López Albújar, "Cómo habla la coca», Cuentos andinos, op.cit. (pp. 248-270), p. 254

51

López Albújar, «La soberbia del piojo», en op.cit., p. 52.

Narrativa indigenista y racismo: Ventura García Calderón, Enrique López Albújar y Luis E. Valcárcel FRANCISCO JOSÉ LÓPEZ ALFONSO 


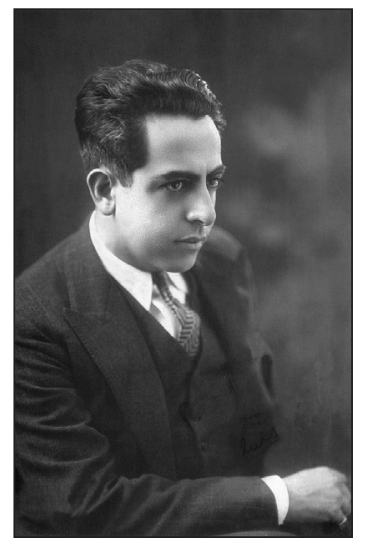

Luis Alberto Sánchez.

52

Ibid., p. 61.

53

Arturo Schopenhaver, El amor, las mujeres y la muerte, Valencia, Ediciones Prometeo, p. 179

\section{4}

López Albújar, «El campeón de la muerte», en op. cit. (pp. 63 87), p. 86

55

López Albújar, «El caso Julio Zimens» en op. cit. (pp. 157. 178), p. 159.

\section{6}

López Albújar, «Cómo habla la coca», op. cit., p. 253

57

González Prada, op. cit., pp. 45-46.

Narrativa indigenista y racismo: Ventura García Calderón, Enrique López Albújar y Luis E. Valcárcel FRANCISCO JOSÉ LÓPEZ ALFONSO occidental; es decir, un ente tan abstracto como la Humanidad o el Bien.

Los indios de Cuentos andinos presentan virtudes que no han pasado desapercibidas: valor, inteligencia, tenacidad, sensibilidad... Pero sobre todo se ha destacado, en relación con la condición de juez del autor, su violencia y su crueldad. Baste recordar las terribles venganzas de Liberato Tucto en «El campeón de la muerte» o de Ishaco en «Cachorro de tigre».

Sin embargo, en ello no hay prejuicio racial. Esa violencia, esa sevicia, es algo general a todos los hombres, como sugiere el desenlace de «La soberbia del piojo», en el que don Melchor, después de contar cómo aplastó entre sus uñas al piojo que le salvó la vida, se defiende sentenciosamente de la acusación que se le formula:

- Fue usted ingrato y cruel

- ¡Bah! Fui todo un hombre, señor mí $0^{52}$.

Y es que López Albújar tiene una concepción del hombre muy próxima a la de Schopenhauer -al que por cierto cita en el último de los relatos-y podría haber afirmado con el filósofo alemán:

El hombre es en el fondo un animal salvaje, una fiera. No le conocemos sino domado, enjaulado en ese estado que se llama civilización. Por eso retrocedemos ante las explosiones de su naturaleza ${ }^{53}$.

Esta concepción de lo humano se ve además subrayada por cierta poética de lo que merece ser contado: «la hazaña más grande de su vida de campeón de la muerte» ${ }^{54}$, «lo más conmovedor que he conocido, lo más triste y lo más trágico también» ${ }^{55}$. Es, pues, una poética del exceso, de lo que se sale en cualquier línea de lo ordinario, también de lo lícito.

En suma, López Albújar no podía idealizar a los indios porque no quería idealizar a los hombres. De esta forma, su indigenismo traspasa la frontera entre cultura indígena y cultura occidental a fin de poder interpretar la totalidad y, más en concreto, la propia cultura con los mismos principios que se aplican a los otros. Al respecto es altamente significativo el último de los relatos, "Cómo habla la coca», en el que el juez narrador se descubre invadido por lo indígena: «Me había dado a la coca. No sé si al peor o al mejor de los vicios. Ni sé tampoco si por atavismo o por curiosidad» ${ }^{56}$.
Cuentos andinos es entonces una interrogación permanente: ¿qué es la identidad?, ¿quiénes somos? Frente al relativismo de los valores como principio general de equivalencia de «todo vale por todo», ese antropológico respeto a las diferencias en el que los investigadores a veces se desdoblan en militantes, López Albújar proclama la necesidad de incorporar al indio a la modernidad. No receta soluciones; solo formula orientaciones.

La modernización del mundo indígena no es fácil, sugiere. No es únicamente una cuestión de economía, ni tampoco de saberes. Es también una cuestión de mentalidades. Y cambiar éstas requiere tiempo. A veces más del que se necesita para que se produzcan cambios en la estructura social.

Pero no era sólo el indio el que debía incorporarse a la modernidad, era toda la región de «estos desventurados campos andinos», sin distinciones de raza o de otra índole. Sin embargo, el atraso material y espiritual de la sierra no redunda, como sucede en La venganza del cóndor, en brillo de Lima, sino en su oprobio, pues en parte era el resultado de su indiferencia por el resto del país. Y López Albújar, no se olvide, era uno de esos provincianos en los que había arraigado con fuerza la prédica radical de González Prada.

En definitiva, el problema se planteaba no sólo desde una perspectiva regional. Y los indios, antes ignorados y hasta despreciados por la cultura oficial, pasaban a ser parte sustancial de la nacionalidad. Pero tampoco la nacionalidad misma, sino un ingrediente más en igualdad con otros grupos humanos, una nacionalidad mestiza en la que el concepto de raza dejaba de tener sentido.

Lamentablemente, los indigenistas interpretaron literalmente el fragmento del «Discurso en el Politeama», en el que González Prada afirmaba que el verdadero Perú, «la nación está formada por las muchedumbres de indios diseminadas en la banda oriental de la cordillera», olvidando que el fragmento iba precedido de estas palabras: «Hablo, señores, de la libertad para todos, y principalmente para los más desvalidos ${ }^{57}$.

Algunos contemporáneos de los novecentistas, como Federico More, fueron indigenistas y lo fueron muchos de los miembros de la generación de la Reforma universitaria, que terminaron por transformar la idea de cultura nacional. Esta nebulosa emocional y demagógica que a menudo fue el indigenismo agrupó 
ideologías muy diversas, desde el marxismo -y a veces el no-marxismo- de Mariátegui hasta posiciones marcadamente burguesas, incluso lindantes con el fascismo.

Pero estos intelectuales indigenistas no eran indios. Mariátegui lo advirtió con claridad. El indigenismo, dijo, «es todavía un literatura de mestizos. Por eso se llama indigenista y no indígena. Una literatura indígena, si debe venir, vendrá a su tiempo. Cuando los propios indios estén preparados para producirla» ${ }^{58}$. El indigenismo era algo más que una moda estética. Los relatos funcionaban como una denuncia del presente y, al mismo tiempo, como un grito de guerra.

Hay, sin embargo, en esta literatura elementos que permiten sospechar que a algunos autores les movían otros intereses distintos del puro afán de justicia. Estos jóvenes intelectuales pertenecían -ya lo he dicho- principalmente al sector medio del ámbito provincial serrano. Pero no escribieron sobre ellos como grupo social o, cuando menos, no lo hicieron de forma directa. En sus relatos tendieron a ocultar su condición. Eran conscientes de que la fuerza moral de sus reivindicaciones había de cimentarse en los desheredados y entre los desheredados nadie más desgraciado que el indígena.

Si los novecentistas predicaron un cambio lento de la sociedad, los indigenistas, que querían un cambio inmediato, se acogieron a la figura del indio como ejemplo extremo de una sociedad que exigía ser transformada sin demora y quizá en profundidad. Autoproclamándose representantes de las muchedumbres indígenas, fingían un poder del que carecían como clases medias.

Tempestad en los Andes, de Luis E. Valcárcel, es el ejemplo más acabado de esta actitud. Publicada en 1927, bajo el «padrinazgo espiritual de Mariátegui» ${ }^{59}$, Tempestad es, en palabras de su autor, una «serie de ensayos y cuadros [descriptivos y narrativos] de la vida actual del indio" ${ }^{60}$. Mariátegui, quien ya había publicado algunas de sus páginas en Amauta, afirmaba en el «Prólogo» que no es «una obra de doctrina ni de teoría. Valcárcel siente resucitar la raza keswa. El tema de su obra es esta resurrección» ${ }^{61}$.

Yo más bien creo que el tema es la amenaza de esta resurrección. De hecho, el mismo Mariátegui añade que Tempestad... «tiene algo de Evangelio y hasta algo de Apocalipsis» ${ }^{62}$. Y Luis Alberto Sánchez, autor del «Colofón», temeroso del carácter sangriento que vaticina Valcárcel para la emancipación del indio, lo reconviene con estas palabras: "No te consuma el odio; el amor es demiurgo', exclama Valcárcel. Y así debiera ser el tono íntegro de este mensaje que nos llega de Cuzco»63.

Valcárcel supo explotar la mala conciencia y el miedo a una guerra de razas. Charlatán de los hechos -los levantamientos y matanzas en algunas haciendas-, escribe con sangre para mostrar como inminente la pesadilla que ya algunos novecentistas habían presagiado:

¡Oh! la esperada Apocalipsis, el Día del Yawar-Inti que no tardará en amanecer.

¿Quién no aguarda la presentida aurora?

El vencedor injusto que ahogará en su propia sangre al indio rebelde. ¿o oís por allí la prédica del exterminio, de la cacería inmisericorde? Ya las matanzas de Huanta, de Cabanillas, de Layo, de cien lugares más son ráfagas del Gran Día Sangriento.

El vencido alimenta en silencio su odio secular; calcula fríamente el interés compuesto de cinco siglos de crueles agravios. ¿Bastará el millón de víctimas blancas? ${ }^{\text {? }}$.

Aunque luego preconice el amor y no el odio, Valcárcel insiste obsesivamente a lo largo de la obra en esa terrible amenaza -los forajidos indios que saquean, violan y asesinan en los pueblos, las haciendas quemadas, los ensañamientos con el patrón, el ejército y la policía integrados casi con exclusividad por indígenas: «Con indios hostiles que vuelven el arma contra blancos y mestizos [...] ¿qué podrá hacer el Estado?»65; insiste de manera meditada para provocar la angustia y favorecer una adhesión sin fisuras a su ofrecimiento.

Entre los textos de Tempestad... hay uno especialmente revelador: «El problema indígena». Se trata de una conferencia leída en la Universidad de Arequipa en la que, después de insistir una vez más en el descenso de los bárbaros, al que no cabe oponerle resistencia -«El block de mestizo-europeo es minúsculo e inerme. Las gentes de color significan el décuplo y han monopolizado el arma»66-, se propone como salvador: «¿Será presunción nuestra -escribe refiriéndose a los intelectuales cuzqueños- el intento de encauzar las formidables energías desplazadas por el mundo que nace detrás de las montañas?» ${ }^{67}$.

Estos intelectuales han tenido el "privilegio [viviendo] en [medio d]el peligro» ${ }^{68} \mathrm{de}$ asistir al despertar de la raza. «En el Cuzco,

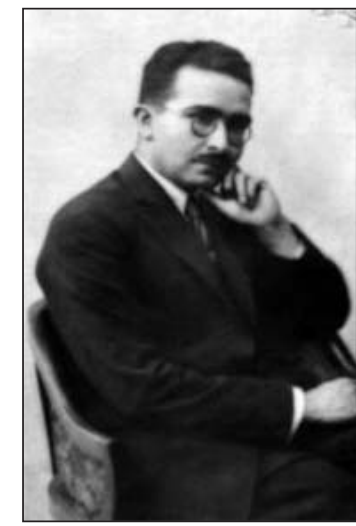

Luis E. Valcárcel.

58

Mariátegui, op. cit., p. 335

59

Valcárcel, "44 años después», Tempestad..., op.cit. (pp. 7-8), p. 7.

60

Carlos Manuel Cox, "Con Luis E. Valcárcel», Amauta, 6 (1927), (pp. 1-2), p. 2.

61

José Carlos Mariátegui, «Prólogo», en Valcárcel, op. cit. (pp. 9-15), p. 9.

62 lbid., p. 15.

63

Luis Alberto Sánchez, "Colofón», en Valcárcel, op. cit. (pp. 177-183), p. 181.

64

Valcárcel, op. cit., p. 24

65

lbid., p. 93.

66

Valcárcel, «El problema indígena», op. cit. (pp. 119-131), p. 125 .

67

Ibid, p. 126

68

Ibid, p. 125

Narrativa indigenista y racismo: Ventura García Calderón, Enrique López Albújar y Luis E. Valcárcel FRANCISCO JOSÉ LÓPEZ ALFONSO 
69

ld.

70

Ibid., pp. 126-127.

71

lbid., p. 127

72

ld.

73

ld.

74

ld.

75

Mariátegui señala en el «Prólogo», op.cit, que la empresa de Valcárcel es la de ayudar "a esa consciencia indígena a encontrarse y revelarse a sí misma», p. 9.

76

Sánchez señala en el "Colofón», op.cit, que el afán de Valcárcel es «noble porque se dirige al humilde», p. 181

77

Valcárcel, «El problema indígena», en op. cit., p. 127.

\section{8}

Véase Valcárcel, «El cura de Kawana», en op. cit., pp. 8082.

79

Así se expresa Mariátegui en el «Prólogo», op. cit., p. 12. Por su parte, Sánchez escribe en el «Colofón», op. cit., "la emancipación social pretende, ahora, surgir de una imitación de Rusia (...)», p. 181.

80

Valcárcel, op. cit., p. 23.

81

Valcárcel, «El problema indígena», en op. cit., p. 127.

82

Valcárcel, op. cit., p. 114.

83

Valcárcel, «El problema indígena», en op. cit., p. 125.

84

Valcárcel, op. cit., p. 107. Llama la atención que, después de la expresión de este prejuicio, Valcárcel ante el auditorio de estudiantes arequipeños afirmase en su conferencia «El problema indígena»: «El mes-

Narrativa indigenista y racismo: Ventura García Calderón, Enrique López Albújar y Luis E. Valcárcel FRANCISCO JOSÉ LÓPEZ ALFONSO

centro de la indianidad los núcleos de la inteligencia están en guardia. La Escuela Cuzqueña [...] hace bastante tiempo que se organiza y disciplina ${ }^{69}$; es decir, se prepara para proponer remedios que impidan o contengan el caos que se avecina.

La única élite posible, capaz de dirigir el movimiento andinista, será integrada por elementos racial o espiritualmente afines al indio, identificados con él, pero con una preparación amplísima, de vastos horizontes y ánimo sereno para afrontar todos los reveses... ${ }^{70}$.

Únicamente Valcárcel, únicamente los miembros de este "grupo selecto»71 estarán capacitados para controlar al «monstruo ciego ${ }^{72}$, únicamente $«$ los obreros intelectuales $»^{73}$ serranos darán forma a su personalidad. «De quienes la guíen -sentencia Valcárcel- depende el futuro» ${ }^{74}$.

Sorprende que tanto Mariátegui ${ }^{75}$ como Sánchez ${ }^{76}$ interpretaran que los destinatarios de este panfleto, al menos parcialmente, eran los indios; sin percibir que, autoproclamándose vocero de las masas campesinas y su jefe natural, era a Lima, como centro político, a la que se le exigía un «Pacto o Contractus»77 para evitar la guerra de razas. Ello significaba que desde Lima se le reconocería un poder del que, en realidad, carecía; pero también que el redentor de indios era, en última instancia, un especialista capaz de manejar métodos más sutiles de dominación; si, naturalmente, obtenía las compensaciones adecuadas. En este sentido podría interpretarse ese elogio de la labor adventista, como instrumento de control, una vez que los indios están abandonando la religión católica ${ }^{78}$.

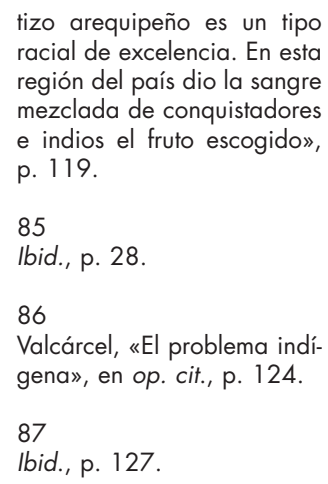

tizo arequipeño es un tipo racial de excelencia. En esta región del país dio la sangre mezclada de conquistadores e indios el fruto escogido», p. 119.

85

Ibid., p. 28.

86

Valcárcel, «El problema indígena», en op. cit., p. 124.

87 Ibid., p. 127.

Y sorprende que tanto Mariátegui como Sánchez creyeran que «Valcárcel resuelve políticamente su indigenismo en socialismo» ${ }^{79}$, cuando el autor de Tempestad clama: «¿Rusia? ¡iEl Perú!!»80; cuando advierte que esa élite rectora de las masas no ha de perder «la ruta en el laberinto de las ideologías» ${ }^{81}$, que el andinismo «no ha menester de extrañas y débiles linternas» ${ }^{82}$.

En realidad, Tempestad está mucho más próxima al fascismo. Como hace éste, negando valor a todas las ideologías, se sirve indiscriminadamente de todas, en una distorsión a la que no le preocupan las contradicciones. $Y$ así, por ejemplo, junto al eslogan «La dictadura indígena espera su Lenin» ${ }^{83}$, encontramos un profundo desprecio por el indígena. El racismo de Valcárcel no se proyecta únicamente sobre el mestizo, ese «nuevo ser híbrido: [que] no hereda las virtudes ancestrales sino los vicios y las taras» ${ }^{84}$. El indio es un «primate anacrónico» ${ }^{85}$, una «masa infrahumana» ${ }^{86}$, «la indiada $»^{87}$.

Adherido a las teorías del volkgeist, el andinismo propuesto por Valcárcel ve en los campesinos la expresión más pura del Perú, pero en su concreción real no dejan de ser una horda bárbara. Imprescindible, pues, esa élite, esa aristocracia nietzscheana que la gobierne y controle, una élite provinciana que habría de sustituir a la «oligarquía desinteresada y enérgica» propuesta por Francisco García Calderón, según Valcárcel ${ }^{88}$. Quítate tú para que me ponga yo. Difícil saber si estábamos ante una renovación del modelo civilista o ante una resurrección del Tawantinsuyo tal y como lo concibió Valcárcel:

Conciliáronse los dos principios comunista y monárquico, dando por fruto un verdadero paternalismo de Estado, a la vez que una sociedad regulada por los principios de cooperación y solidaridad ${ }^{89}$.

No estaba exento de cierta razón Alcides Arguedas cuando hacía afirmar al narrador de Raza de bronce que los defensores del indio se dividen casi invariablemente en dos categorías: «los líricos que no conocen al indio y toman su defensa como un tema fácil de literatura, o los que, también sin conocerle, toman la causa del indio como un medio de medrar y crear inquietudes exaltando sus sufrimientos, creando el desconcierto, sembrando el odio con el fin de medrar a su hora apoderándose igualmente de sus tierras» ${ }^{90}$. 